\title{
NÍVEL DE MATURIDADE EM GERENCIAMENTO DE PROJETOS: ESTUDO DE CASO EM EMPRESA FAMILIAR DE MÉDIO PORTE DO RAMO ALIMENTÍCIO
}

\author{
MATURITY LEVEL IN PROJECT MANAGEMENT: \\ CASE STUDY IN A MEDIUM-SIZED FAMILY BUSINESS IN THE FOOD INDUSTRY
}

Cassius Alexandre Geremia Mestrando em Administração e Ciências Contábeis Universidade Comunitária da Região de Chapecó - UNOCHAPECO. São Lourenço do Oeste, Santa Catarina - Brasil. cassius@unochapeco.edu.br

Daniela Carine Schmitt Mestranda em Administração e Ciências Contábeis Universidade Comunitária da Região de Chapecó - UNOCHAPECO. São Lourenço do Oeste, Santa Catarina - Brasil. daniela.schmitt@unochapeco.edu.br

\begin{abstract}
Cleunice Zanella Doutora em Administração pela UFSC Professora do programa de Pós-Graduação em Administração e Ciências Contábeis pela Universidade Comunitária da Região de Chapecó - UNOCHAPECO. Chapecó - Brasil.

cleunice@unochapeco.edu.br
\end{abstract}

Resumo

A utilização de métodos e técnicas para a gestão de projetos pode aferir o nível de maturidade das empresas, aumentando a probabilidade de alcance dos resultados esperados. Avaliar o nível de maturidade de gerenciamento de projetos pode ser útil à medida que possibilita a identificação de gaps, pontos fracos, bem como pontos fortes, visando a melhoria contínua da gestão de projetos. O objetivo deste estudo é analisar o nível maturidade de gerenciamento de projetos de uma empresa familiar do ramo alimentício localizada no oeste catarinense. $\mathrm{O}$ estudo caracteriza-se como estudo de caso de natureza descritiva, com abordagem quantitativa. A ferramenta de análise utilizada foi o Modelo de Maturidade de Gestão de Projetos - MMGP. O instrumento foi respondido por 21 funcionários da empresa que possuem relação direta com a elaboração e execução dos projetos. Os resultados indicaram um nível de maturidade fraca, com média de 2,45, o que indica possibilidade a melhoria através de investimento em treinamentos, implantação plataforma informatizada e padronização de práticas para alcançar gradualmente níveis maiores de absorção de gerenciamento. A contribuição teórica do presente estudo ocorre em função de ser um estudo aplicado no ambiente de empresas familiares fazendo uso da ferramenta MMGP, o qual preencheu uma lacuna da literatura científica, além de seus dados servirem de base para o desenvolvimento da maturidade de projetos em outras empresas familiares.

Palavras-Chave: Gerenciamento de Projetos. Nível de Maturidade. Empresa Familiar. Modelo de Maturidade de Gestão de Projetos. MMGP.

\begin{abstract}
The use of methods and techniques for project management can measure the maturity level of companies, increasing the probability of achieving the expected results. Assessing the level of project management maturity can be useful as it allows the identification of gaps, weaknesses, as well as strengths, aiming at the continuous improvement of project management. This study aims to analyze the level of project management maturity of a family-owned food company located in western Santa Catarina. The study is characterized as a case study of a descriptive nature, with a quantitative approach. The analysis tool used was the PMMM - Project Management Maturity Model. The
\end{abstract}


instrument was answered for 21 company employees who have a direct relationship with the preparation and execution of projects. The results indicated a low level of maturity, with an average of 2.45 , which indicates the possibility of improvement through investment in training, implementation of a digital platform, and standardization of practices to gradually achieve higher levels of management absorption. The theoretical contribution of this study is because it is an applied study in the environment of family businesses using the MMGP tool, which filled a gap in the scientific literature, in addition to its data serving as a basis for the development of project maturity in other family businesses.

Keywords: Project Management. Maturity Level. Enterprise Management. Project Management Maturity Model. PMMM.

\section{Cite como - American Psychological Association (APA)}

Geremia, C. A., Schmitt, D. C., \& Zanella, C. (2020, maio/ago.). Nível de maturidade em gerenciamento de projetos: estudo de caso em empresa familiar de médio porte do ramo alimentício. Revista de Gestao e Projetos (GeP), 11(2), 110-132.

https://doi.org/10.5585/gep.v11i2.16911.

\section{Introdução}

As constantes mudanças impostas às empresas exigem rápidas adequações e informações precisas para a tomada de decisão (Pires, 2014). A utilização de melhores práticas para o gerenciamento de projetos possibilita às empresas o estabelecimento de processos bem definidos, os quais podem gerar maior agilidade e melhor desempenho organizacional (Paiva, 2010). Neste sentido, métodos e técnicas de gestão de projetos podem agilizar os processos organizacionais e facilitar a tomada de decisões frente mudanças atuais nas organizações é a utilização da gestão de projetos (Sgura, Araujo \& Lopes, 2015).

A relevância da gestão de projetos nas empresas fica evidente pelo estabelecimento de uma metodologia que se adapta em cada organização, e que ao mesmo tempo respeita a cultura interna para poder garantir a sobrevivência e o diferencial competitivo no mercado atual (Campos, 2020).
O entendimento da real importância da gestão de projetos nos mais variados segmentos empresariais tem ganhado destaque na literatura recente (Cardoso, Ziviani \& Duarte, 2017; Patrício \& Neto, 2019). Porém, destaca-se que as empresas brasileiras têm sido lentas na adoção de práticas de gestão de projetos, devido, especialmente, a fatores relacionados à estratégia e comportamento da alta administração, bem como a ausência de capital humano e de capacitações, além da cultura organizacional (PMI, 2017). Neste sentido, torna-se importante avaliar o nível de maturidade de gestão de projetos, visto que, de acordo com PMI (2017), a eficiência da gestão de projetos passa pelo amadurecimento dos sistemas e metodologias utilizadas pelas empresas.

Modelos para a avaliação da maturidade em gerenciamento de projetos têm obtido destaque cada vez mais notório, por meio de esforços vinculados ao gerenciamento 
de projetos, desenvolvendo competências organizacionais (Patrício \& Neto, 2019). As empresas têm ao seu dispor uma elevada gama de métodos para avaliar o nível de maturidade de gestão de projetos (Silva, Monteiro \& Junior, 2018), a literatura científica por sua vez, procura auxiliar na composição dos melhores modelos para cada realidade (Costa \& Ramos, 2013), cabendo ao gestor de projetos o conhecimento para reconhecer e aplicar a metodologia mais coerente para seu ambiente (Santos, Schramm \& Schramm, 2019).

Destaca-se nesse contexto a utilização neste estudo do Modelo de Maturidade em Gerenciamento de Projetos (MMGP) (Prado, 2010), por ser aderente a realidade das empresas de pequeno e médio porte, e de constituição familiar, visto que as empresas familiares sofrem influência significativa no estilo de gestão (Kammerland \& Essen, 2017; Vinagre et al., 2017), fator esse que pode influenciar o nível de maturidade de gestão de projetos. Vários estudos foram recentemente realizados utilizando a metodologia MMGP (Campos et al., 2020; Oliveira, 2014; Abrahão \& Oliveira, 2016; Scotelano et al., 2017; Cardoso, Ziviani \& Duarte, 2017; Silva, Monteiro \& Junior, 2018; Patrício \& Neto, 2019; Arruda et al., 2019), demonstrando resultados com níveis fortes de maturidade de projetos.

Enquanto que outras pesquisas obtiveram resultados com nível de maturidade regular, como no caso de:
Santos, Schramm e Schramm (2019) em uma empresa de construção civil que atua no nordeste do Brasil, Sgura, Araujo e Lopes (2015) em uma empresa Fabricante de Cabos Submarinos para Poços de Exploração de Petróleo. E por fim, com nível de maturidade boa: Farias et al. (2018) na agência de saneamento de Paragominas no Pará. As pesquisas correlatas analisadas confirmam que o nível de maturidade do gerenciamento de projetos é relevante em todos os aspectos empresariais, sendo desta maneira um vetor de minimização de problemas de gerenciamento. Diante desse contexto, verificou-se oportunidades de analisar o nível de maturidade em gestão de projetos em pequenas e médias empresas do segmento alimentício (Rabechini \& Pessoa, 2005). Além do ineditismo da aplicação do referido modelo em empresas familiares, por não serem encontradas aplicações nas bases consultadas.

Entende-se haver necessidade de estabelecer inter-relações entre a gestão de projetos nas empresas de pequeno e médio porte, e o nível de maturidade deste gerenciamento de projetos, e posteriormente discuti-las, contribuindo para que as empresas possam compreender melhor suas questões gerenciais e auxiliar na resolução de possíveis problemas, contribuindo assim com o desenvolvimento destas organizações e com a literatura. Para o alcance dos resultados, a partir da lacuna de pesquisa, parte-se do seguinte questionamento de pesquisa: Qual é o nível de maturidade de gerenciamento de 
projetos em uma empresa familiar do ramo alimentício? Tendo como objetivo analisar o nível maturidade de gerenciamento de projetos de uma empresa familiar do ramo alimentício localizada no oeste catarinense.

Os resultados do presente estudo possibilitam determinar que o nível de maturidade encontra-se em um patamar fraco 2,45. Assim, é possível apresentar um diagnóstico para a empresa detectar pontos à serem melhorados. A pesquisa corrobora com a literatura na discussão dos achados, preenchendo a lacuna identificada e também como base para novos estudos, em novos ambientes, novos perfis de organizações ou mesmo outras variáveis a serem analisadas.

$\mathrm{O}$ artigo está estruturado em seis seções, sendo esta com a contextualização do tema, apresentação do problema, objetivos e justificativas, após será apresentado o desenvolvimento da revisão da literatura dividido em quatro subseções: gestão de projetos, maturidade em gerenciamento de projetos, gestão de projetos em empresas familiares e estudos correlatos. Na seção três serão apresentados os procedimentos metodológicos, após serão discutidos e apresentados os resultados, e ao final serão tecidas as conclusões e apresentadas as referências bibliográficas.

\section{Gestão de Projetos}

A formalização da gestão de projetos surgiu em meados da década de 1950 e a partir de então têm ocorrido grandes avanços. Em
1969, a criação do Project Management Institute (PMI), ficou marcada como o início da evolução desta temática no ambiente empresarial (PMI, 2017). Já na década de 1970 algumas universidades americanas, abordaram em seus estudos a precariedade da gestão de projetos nas empresas e a partir dessa iniciativa, realizaram a formalização destas atividades (Brown, 2008; Farias et al., 2018). A metodologia de gestão de projetos foi inicialmente utilizada por empresas de construção, aeroespacial e da defesa, dos Estados Unidos, Canadá, Europa e Japão (Silva \& Feitosa, 2012). Já a partir da década de 1980, a gestão de projetos percebe outras atribuições, incorporando a visão da satisfação do cliente como fator mensurável, e por último, foi introduzida a gestão em conjunto com a integração das diversas áreas, com o objetivo de efetuar melhorias na gestão de riscos, transformando assim em uma ferramenta de estratégia organizacional para as empresas (Srivannaboon, 2009; Sgura, Araujo \& Lopes, 2015).

A gestão de projetos em seu conceito base refere-se à aplicação de um conjunto de conhecimentos, habilidades, ferramentas e técnicas com o objetivo de atender os requisitos para execução de projetos (Oliveira, 2014). A gestão de projetos busca integrar 47 processos relacionados ao escopo dos projetos, os quais abrangem 5 grupos de processos: Iniciação, Planejamento, Execução, Monitoramento e Controle e Encerramento (PMI, 2017). 
Uma das premissas da gestão de projetos é proporcionar uma abordagem relevante ao cenário, com o objetivo de criar um ambiente de excelência na empresa (Brown, 2008; Silva, Monteiro \& Junior, 2018). Para que seja possível o alcance dos objetivos da gestão de projetos, é preciso determinar um processo formal na abordagem organizacional, desenvolvendo uma cultura organizacional de suporte aos processos organizacionais. $\mathrm{O}$ estabelecimento de um papel de liderança apropriado para os gestores dos projetos permite o acesso de forma igualitária e livre a dados e informações para os membros da equipe a fim facilitar os processos de gerenciamento. $\mathrm{O}$ compartilhamento destes dados contribui para o estabelecimento de uma relação de colaboração mútua e de confiança entre os membros das equipes participantes e dos gestores do projeto (Karlsen, 2010).

A gestão de projetos é entendida como uma aplicação prática, e de projeção social, a qual é construída por meio de ferramentas, métricas e técnicas desenvolvidas para proporcionar suporte à atividade de gestão (Crawford, 2006; Arruda et al., 2019). Também são atribuições da gestão de projetos identificar os requisitos e expectativas das partes interessadas, ajustando as diferenças necessárias para que isso ocorra no decorrer do desenvolvimento do projeto, cabendo ao gestor de projetos o balanceamento e equilíbrio dos conflitos vinculados a escopo, qualidade, cronograma, orçamento, recursos e riscos (PMI, 2017).

Por fim, destaca-se que para Silva e Feitosa (2012) a gestão de projetos caracterizase como sendo um campo de prática, o qual apresenta como o objetivo principal planejar, monitorar e controlar as ações do projeto e racionalização dos recursos, utilizando-se de instrumentos, ferramentas e técnicas, para desenvolver os requisitos previamente determinados, para que os prazos e custos sejam atendidos.

\subsection{Maturidade em gerenciamento de projetos}

Em termos práticos, a maturidade em gerenciamento de projetos pode ser entendida como um nível em que a empresa constrói uma base suficiente de ferramentas, técnicas e processos, de maneira que ao final do projeto os gestores sejam capazes de compreender e discutir criticamente a metodologia utilizada, além de desenvolver recomendações e aprender com as falhas cometidas (Crawford, 2006; Campos et al., 2020). A maturidade em gestão de projetos também indica um conjunto de processos, com uma carga pré-definida de níveis de capacidade, que possuem características repetitivas e geram uma grande probabilidade de sucessos individuais, contudo, esses fatores não são garantia de sucesso, apenas auxiliam no aumento da proatividade (Cardoso, Ziviani \& Duarte, 2017).

Quando se fala em excelência em gestão de projetos, pode-se estar confundindo 
com o termo maturidade em gerenciamento de projetos, porém estes são conceitos distintos, visto que a excelência é um conceito mais sólido, o qual vai além da maturidade, sendo a maturidade é-um pré-requisito para alcançar a excelência em gestão de projetos (Santos, Schramm \& Schramm, 2019). Logo, a excelência em gestão de projetos é alcançada se a organização alcançar um excelente nível de maturidade (Farias et al., 2018).

$\mathrm{O}$ desenvolvimento de ferramentas e processos com altos níveis de maturidade permitem que as atividades sejam executadas de maneira a causarem o mínimo de problemas para os negócios das empresas (Arruda et al., 2019). Os modelos de maturidade permitem identificar em qual nível as empresas atualmente se enquadram e também auxiliam na definição do próximo nível em que a organização pode estar inserida (Silva, Monteiro \& Junior, 2018). Os modelos de maturidade em gestão de projetos são concebidos para fornecer a estrutura de trabalho necessária que uma empresa necessita para continuamente desenvolver suas habilidades para executar projetos de forma exitosa (Patrício \& Neto, 2019).

Devido a relevância dos resultados obtidos a partir dos modelos de maturidade em gerenciamento de projetos para as empresas, pesquisadores e universidades vêm desenvolvendo modelos que proporcionam o desenvolvimento das habilidades em gerenciamento de projetos (Campos et al., 2020). Os modelos de maturidade utilizam índices numéricos para identificar os níveis de maturidade de uma organização. Com o auxílio destes modelos é possível às organizações desenvolverem processos e atividades com o auxílio das melhores práticas do mercado, para o desenvolvimento progressivo de seus projetos (Prado, 2010). Outra atribuição do modelo de maturidade é identificar de que forma a capacitação em gestão de projetos deve progredir.

$\mathrm{O}$ primeiro modelo de maturidade criado na literatura foi o Capability Maturity Model (CMM), o qual foi desenvolvido em 1997 na Carnegie Mellon University. Este modelo permite descrever os estágios de maturidade a partir dos quais as empresas transitam enquanto progridem em sua cadeia de desenvolvimento, com foco em uma estratégia de melhorias contínuas dos processos. As melhorias neste modelo são definidas em cinco níveis de maturidade: 1) Inicial; 2) Repetível; 3) Definido; 4) Gerenciado; 5) Otimização (Paulk, Weber, Curtis \& Chrissis, 1995). Existe um número relevante de modelos na literatura atual, mas aqui será apresentado o Modelo de Maturidade em Gerenciamento de Projetos MMGP desenvolvido por Prado (2010).

O MMDP desenvolvido, por meio de uma pesquisa aplicada para 261 profissionais de diversas empresas brasileiras. O modelo é composto por 5 níveis e 6 dimensões, as quais possuem um métodos de intervenção através de um questionário de 40 questões que integram a maturidade da empresa com a 
capacidade de desenvolver projetos bem gráfica do modelo MMGP. sucedidos. A Figura 1 demonstra a ilustração

Figura 1 - Níveis de maturidade do Modelo MMGP

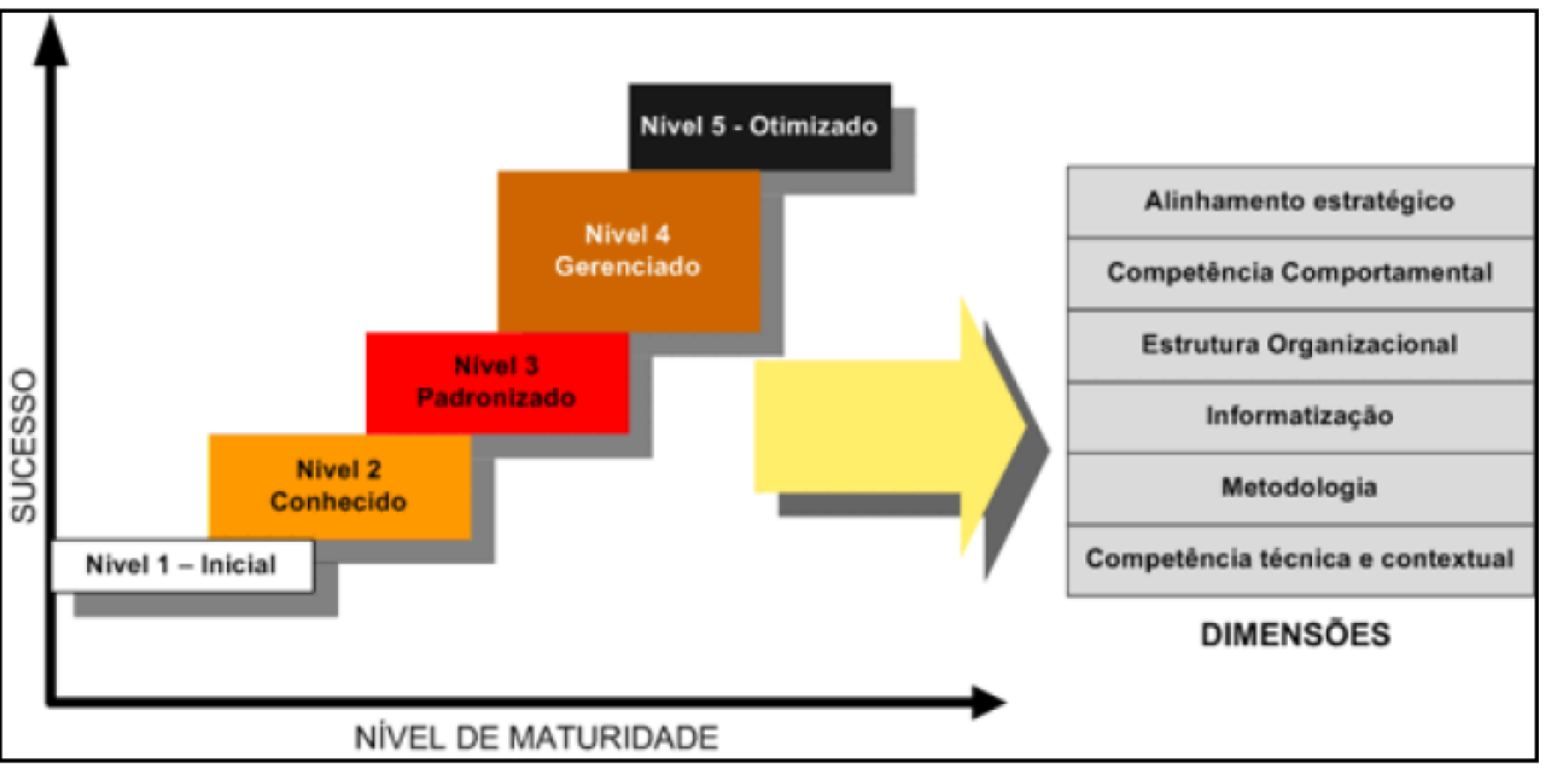

Fonte: Costa e Ramos (2013, p. 240).

O modelo utiliza seis dimensões para desenvolver a aplicação: 1) alinhamento estratégico; 2) Competência técnica e contextual; 3) Metodologia; 4) Informatização; 5) Estrutura organizacional; e 6) Competência comportamental (Prado, 2010). Além das dimensões, o modelo propõe cinco níveis para determinação da aplicação, os quais são: 1) Inicial ou Embrionário: este representa um cenário inicial, no qual a entidade não desenvolveu nenhum esforço para o desenvolvimento de um modelo de gestão de projetos; 2) Conhecido: este representa o cenário em que a empresa desenvolveu alguma iniciativa em gestão de projetos para criação uma linguagem comum para o assunto; 3) Padronizado: é o cenário em que a entidade implanta um modelo padronizado para gestão de projetos, com base em recursos computacionais, estrutura organizacional e metodologias; 4) Gerenciado: com base nas ações iniciadas no nível anterior são consolidadas as bases como metodologia, informatização, estrutura organizacional e alinhamento estratégico; e 5) Otimizado: este nível representa um momento em que a empresa atinge a capacidade máxima em gerenciamento de projetos (Prado, 2010).

\subsection{Gestão de projetos em pequenas e médias empresas}

Os problemas característicos das pequenas e médias empresas quanto suas atividades de gestão motiva a adoção de ferramentas e modelos de auxílio à 
administração (Kammerland \& Essen, 2017).

As organizações buscam no conhecimento formas de superar as dificuldades encontradas no dia-a-dia destas, o gerenciamento de projetos pode ser uma destas ações (Rabechini \& Pessoa, 2005).

Algumas dificuldades são características com a gestão de pequenas e médias empresas, como a dificuldade de delegar poder de decisão e falta de formalização nos projetos de gestão (Sá Freire, Pereira, Keiko, \& Spanhol, 2010). Outro fator preponderante na dificuldade de formalização nestas empresas é o fato de serem administradas, muitas vezes, ainda pelo fundador ou sócio proprietário, pois seu ego e sua ligação emocional com a empresa são muito presentes, assim frente à possíveis problemas há uma dificuldade do mesmo renunciar ao controle.

A maturidade em gerenciamento de projetos das empresas de pequeno e médio porte continuamente torna-se o foco de muitos proprietários e gestores. Essa prática desencadeia no aumento do profissionalismo o processo de maturação da gestão de projetos. Além destes benefícios também ocorre a prática da formalização das atividades nas empresas (Rabechini \& Pessoa, 2005; Kammerland \& Essen, 2017). As certificações profissionais podem auxiliar os gestores atuantes nas pequenas e médias empresas a desenvolverem-se no processo de amadurecimento e profissionalismo na execução dos processos de gestão, entre estas, destaca-se a certificação Project Management Professional (PMP), a qual possui reconhecimento mundial e figura como a mais alta certificação neste contexto. Quando as empresas possuem colaboradores com essa certificação, apresentam um nível mais elevado de maturidade em gestão de projetos (Patrício \& Neto, 2019).

A utilização de metodologias de gestão de projetos em pequenas e médias empresas ajuda a promover um cenário de vantagens competitivas, por meio da formalização de processos e inovações do mercado, seja através de um novo empreendimento ou uma nova atividade interna, as quais têm como objetivo novos mercados e a busca da inovação contínua (Ireland, Hitt \& Sirmon, 2003; Vinagre et al., 2017).

No contexto das empresas familiares, para Kammerland e Essen (2017), de certa maneira estas empresas são conhecidas pelo não apego ao risco, conservadoras e estagnadas. Assim Vinagre et al. (2017), destaca que a filosofia da vida familiar influencia significativamente no estilo da gestão. Alheio a estas vertentes de perfil dos gestores, Estol e Fereira (2006), salienta que um dos estágios da empresa familiar é a maturidade de seus projetos, possuindo rotinas bem estabelecidas.

\subsection{Estudos correlatos}

Alguns estudos foram desenvolvidos com a temática relacionada a maturidade da 
gestão de projetos. O estudo de Oliveira (2014) avaliou em sua pesquisa o nível de maturidade em gerenciamento de projetos no setor de Engenharia de Projetos de um Estaleiro de grande porte no nordeste brasileiro, partindo da análise das respostas através do Modelo MMGP. Para o alcance dos objetivos, os questionários foram distribuídos entre gerentes e coordenadores, após a coleta os dados foram analisados através das ferramentas propostas pelo estudo. Os resultados apontaram para um nível de maturidade em gerenciamento de projetos considerado fraco quando comparado com diversas empresas de outros segmentos, indicando necessidade de planos de melhoria.

O estudo de Scotelano et al. (2017) discute os conceitos teóricos relacionados ao gerenciamento de projetos, através dos conceitos de modelos de maturidade. São apresentados os resultados de uma pesquisa realizada em uma indústria automobilística no Brasil, por meio da pesquisa de maturidade MMGP. O resultado encontrado revelou que a organização analisada está nos níveis observados e calculados, considerando o nível médio de maturidade da região e do país. Concluiu-se que a metodologia brasileira adotada foi eficaz em termos de mensuração do nível de maturidade em uma organização brasileira.

O estudo de Cardoso, Ziviani e Duarte (2017) utilizou o modelo de MMGP, no qual os resultados apontaram que as empresas pesquisadas estão no patamar dito como conhecido ou nível dois. Neste grau de maturidade, as empresas apresentam ações esporádicas, reatividade de grande parte da equipe de trabalho, baixo interesse da alta administração e estímulo à visão estratégica de curto prazo. Ficou evidenciado que o alcance das metas estabelecidas para os projetos é atingido mais facilmente na medida em que ocorre o alinhamento estratégico dos projetos com a organização e na existência de capacitação técnica da equipe.

Campos et al. (2020) desenvolveram uma pesquisa cujo objetivo foi avaliar a maturidade da capacidade organizacional da UFAL em gerenciar projetos utilizando a metodologia MMGP indicando onde se deve investir para obter melhores resultados. A contribuição teórica dessa pesquisa deu-se em função de ser o primeiro trabalho no contexto universitário a fazer o uso dessa ferramenta, o que se constitui em uma lacuna a ser explorada, além de servir de incentivo a adoção dessa metodologia por parte de outras Instituições de Ensino Superior. A nota final da organização foi 1,64 em uma escala ordinal de 1 até 5 , classificando-a como nível 2 de maturidade, o que indica que se deve investir em treinamento, na implantação de uma plataforma informatizada e na padronização de suas práticas.

\section{Procedimentos Metodológicos}

A pesquisa classifica-se como estudo de caso de caráter descritivo com uma abordagem quantitativa, realizado por meio da coleta de dados com auxílio de um 
questionário. Caracteriza-se quanto ao método de intervenção, como um estudo de caso com a coleta de dados a por meio de questionário (Gil, 2002) e também como indicado por Yin (2005), a utilização de questionários, é conceituado com uma forma de coletar dados e informações a partir de características e opiniões de grupos de indivíduos. Quanto a abordagem do problema, descritivo, ao analisar as práticas adotadas pela amostra estudada descrevendo o fenômeno estudado, e quantitativo pelo tratamento dos dados $\mathrm{e}$ análise aos resultados obtidos pelo questionário aplicado (Gil, 2002; Yin, 2005).

A população é composta por 28 pessoas, sendo 8 gestores e 20 supervisores, já a amostra de pesquisa é composta por 21 colaboradores, dentre eles 6 gerentes e 15 supervisores de uma empresa de médio porte, a qual conta com um quadro colaborativo de aproximadamente 620 funcionários da data da coleta de dados. Esta amostra contempla todos os setores da empresa, porém somente os representantes de maiores níveis hierárquicos, pois os mesmos possuem relação com a gestão de projetos, o que não seria possível com todos os colaboradores dos níveis operacionais.

Para coleta dos dados foi utilizado o MMGP desenvolvido por Prado (2010). Esse modelo é expresso por um questionário que consiste na aplicação de 10 questões para cada um dos 4 níveis, totalizando 40 questões. Cada questão possui 5 alternativas para resposta, representando os níveis de maturidade e os 6 elementos de dimensões. O instrumento indica um peso para cada questão, as quais são representadas pelos valores 10, 7, 4, 2 e 0, para as questões A, B, C, D e E, respectivamente.

Após o levantamento e totalização dos pontos apurados em cada questão, pode-se mensurar a avaliação final de maturidade, através da fórmula:

\section{Avaliação Final da Maturidade $($ AFM $)=(100$ + total de pontos) / 100}

A aplicação dos questionários aos respondentes ocorreu no período de 25/11/2019 a 10/12/2019. Primeiramente foram agendados pelos pesquisadores os horários para todos os respondentes, os quais realizaram toda a coleta de forma presencial com um tempo livre de uma hora e vinte minutos para resposta de todo questionário, havendo uma sobra de tempo estimada de vinte minutos para cada entrevistado. Os questionários foram aplicados de forma impressa em papel para todos os respondentes, somente após a coleta de todos os 21 questionários é que foram transferidos para uma planilha eletrônica para posterior tratamento. Após a finalização da coleta de dados, obteve-se 21 respostas, representando uma amostra de $75 \%$ em relação ao universo determinado para pesquisa, o qual era composto por 28 colaboradores.

A análise dos resultados foi elaborada após a coleta dos dados primários transmitidos para planilhas eletrônicas de apoio. Primeiramente foram tabuladas as questões de 
cada respondente, bem como com sua caracterização. Posteriormente por meio da mesma planilha foram desenvolvidas as informações, tanto para o nível de maturidade, como as dimensões, para assim transferi-la na forma de gráficos.

\section{Apresentação e Discussão dos Resultados}

A empresa pesquisada está sediada em um município de aproximadamente 25.000 habitantes, no Oeste do estado de Santa
Catarina, se enquadra como de médio porte, sendo uma SA (sociedade anônima) de capital fechado. Sua atividade está voltada ao setor alimentício com gestão familiar, possuindo aproximadamente $620 \quad$ colaboradores, divididos nos setores produtivos, logística, suprimentos, comercial, recursos humanos, contábil, projetos, tecnologia da informação e financeiro. A Tabela 1 apresenta a caracterização da amostra pesquisada.

Tabela 1 - Caracterização da amostra

\begin{tabular}{|c|c|c|}
\hline Gênero & Quantidade & $\%$ \\
\hline Masculino & 16 & 76,2 \\
\hline Feminino & 5 & 23,8 \\
\hline Total & 21 & 100 \\
\hline Idade & Quantidade & $\%$ \\
\hline Até 25 anos & 0 & 0 \\
\hline 25 a 35 anos & 8 & 38,1 \\
\hline 35 a 45 anos & 10 & 47,62 \\
\hline Mais de 45 anos & 3 & 14,28 \\
\hline Total & 21 & 100 \\
\hline Nível de Escolaridade & Quantidade & $\%$ \\
\hline Ensino Fundamental & 0 & 0 \\
\hline Ensino Médio & 0 & 0 \\
\hline Graduação & 14 & 66,67 \\
\hline Pós Graduação/Especialização & 7 & 33,33 \\
\hline Total & 21 & 100 \\
\hline Tempo de empresa & Quantidade & $\%$ \\
\hline Até 5 anos & 10 & 47,62 \\
\hline De 05 a 15 anos & 7 & 33,33 \\
\hline De 15 a 25 anos & 3 & 14,28 \\
\hline Acima de 25 anos & 1 & 4,77 \\
\hline Total & 21 & 100 \\
\hline
\end{tabular}


Geremia, C. A., Schmitt, D. C., \& Zanella, C. (2020, maio/ago.). Nível de maturidade em gerenciamento de projetos: estudo de caso em empresa familiar de médio porte do ramo alimentício

\begin{tabular}{ccc}
\hline Função exercida & Quantidade & $\%$ \\
\hline Gerencia & 6 & 28,6 \\
Supervisão & 15 & 71,4 \\
Total & 21 & 100 \\
\hline Tempo na função & Quantidade & $\%$ \\
\hline Até 3 anos & 12 & 57,15 \\
De 03 a 05 anos & 3 & 14,28 \\
De 05 a 15 anos & 5 & 23,8 \\
Acima de 15 anos & 1 & 4,77 \\
Total & 21 & 100 \\
\hline
\end{tabular}

Fonte: Elaborado pelos autores.

O setor de projetos especificamente conta atualmente com três profissionais. É o setor que foi constituído mais recentemente na empresa, há aproximadamente 5 anos, e atingiu seu pico de profissionais entre $2015 \mathrm{e}$ 2016, quando possuía cinco colaboradores no quadro, por conter projetos mais robustos, dentre eles, a construção do novo centro administrativo.

Dentre as atribuições do setor de gestão de projetos, pode-se citar genericamente, levantamento técnico de linhas produtivas, documentação e memorial técnico, desenvolvimento de layouts, levantamento de orçamentos e monitoramento, gerenciamento e readequação de custos e prazos de projetos. Historicamente a empresa possui 105 projetos desenvolvidos pelo setor de gestão de projetos, segue na Tabela 2, o volume de cada ano.

Tabela 2 - Quantidade de desenvolvimento de projetos por ano

\begin{tabular}{lc}
\hline Ano & Quantidade de Projetos \\
\hline 2015 & 16 \\
2016 & 16 \\
2017 & 30 \\
2018 & 24 \\
2019 & 19 \\
\hline Total & $\mathbf{1 0 5}$ \\
\hline
\end{tabular}

Fonte: Elaborado pelos autores. 
A queda do número de projetos no ano de 2019 em relação aos anos de 2018 e 2017 se dá pelo fato que a empresa modificou a política de investimentos com captação pública no ano de 2019, passando a restringir o volume de investimentos em projetos de melhoria e ampliação. Logo os projetos desenvolvidos no último ano citado requerem investimentos de recursos financeiros menores que os demais anos. O acompanhamento destes projetos pela equipe responsável, auxilia no desenvolvimento e alocação dos recursos de forma mais assertiva, aumentando o reflexo positivo dos investimentos, da mesma forma que é discutido no trabalho de Cardoso, Ziviani e Duarte (2017).

Após a aplicação dos questionários, os dados foram tabulados em planilha Excel, sendo alimentada a pontuação de cada pergunta. A partir disso, foi obtido o nível de maturidade de cada respondente, bem como a maturidade final geral, conforme a Figura 2.

Figura 2 - AFM geral e AFM por respondentes

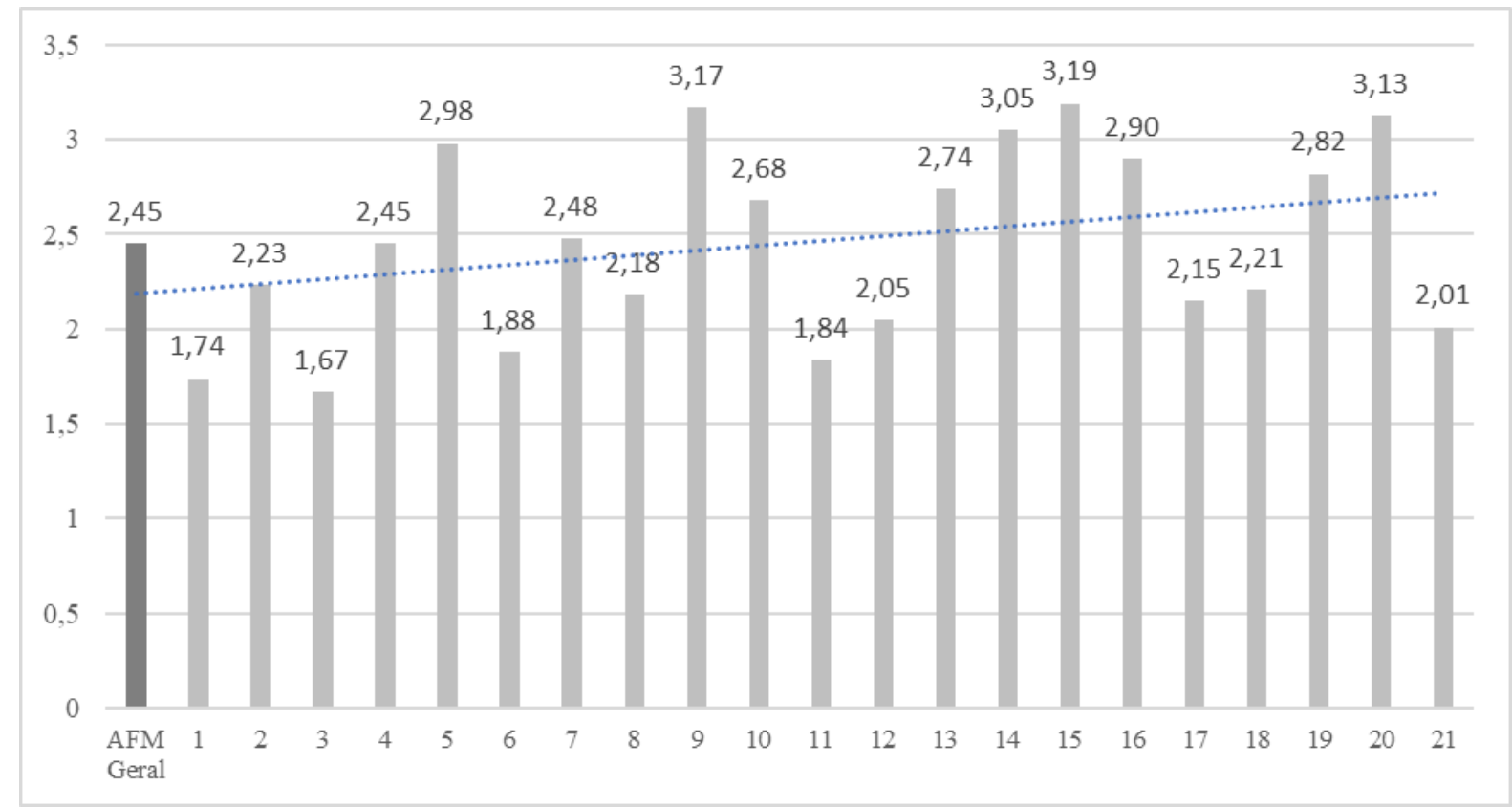

Fonte: Elaborado pelos autores.

Conforme representado na Figura 2, a Avaliação Final de Maturidade (AFM) encontrada de acordo com a fórmula de AFM detalhada no capítulo anterior de 2,45, sendo um desvio padrão encontrado de 0,49, considerado uma variação de certo modo, levemente heterogênea, pois, sendo observado que o menor índice individual de AFM, verificado no respondente 3 , com 1,67 , e o maior índice encontrado no respondente 15 , com índice AFM 3,19. Verifica-se que os maiores índices ocorreram pelos respondentes 
do nível de supervisão (exemplo: respondente $5,9,14,15$ e 20), significando que mesmo obtendo índices maiores, os projetos da empresa possuem um nível de maturidade inadequado, necessitando ações pontuais para concretização do nível de maturidade e aumento da credibilidade na implantação destes projetos. Uma ação adequada para o caso da empresa pesquisada, é a implementação de um escritório de projetos com colaboradores com experiência em desenvolvimento de projetos e adoção de estratégias de benchmarking.

Dentre as pontuações extraídas deste modelo, segue as pontuações em cada nível analisado, diferenciando os cargos de gerentes e supervisores, de acordo com a Figura 3, apontados nesta amostra.

Figura 3 - Pontuação por nível entre gestores e supervisores

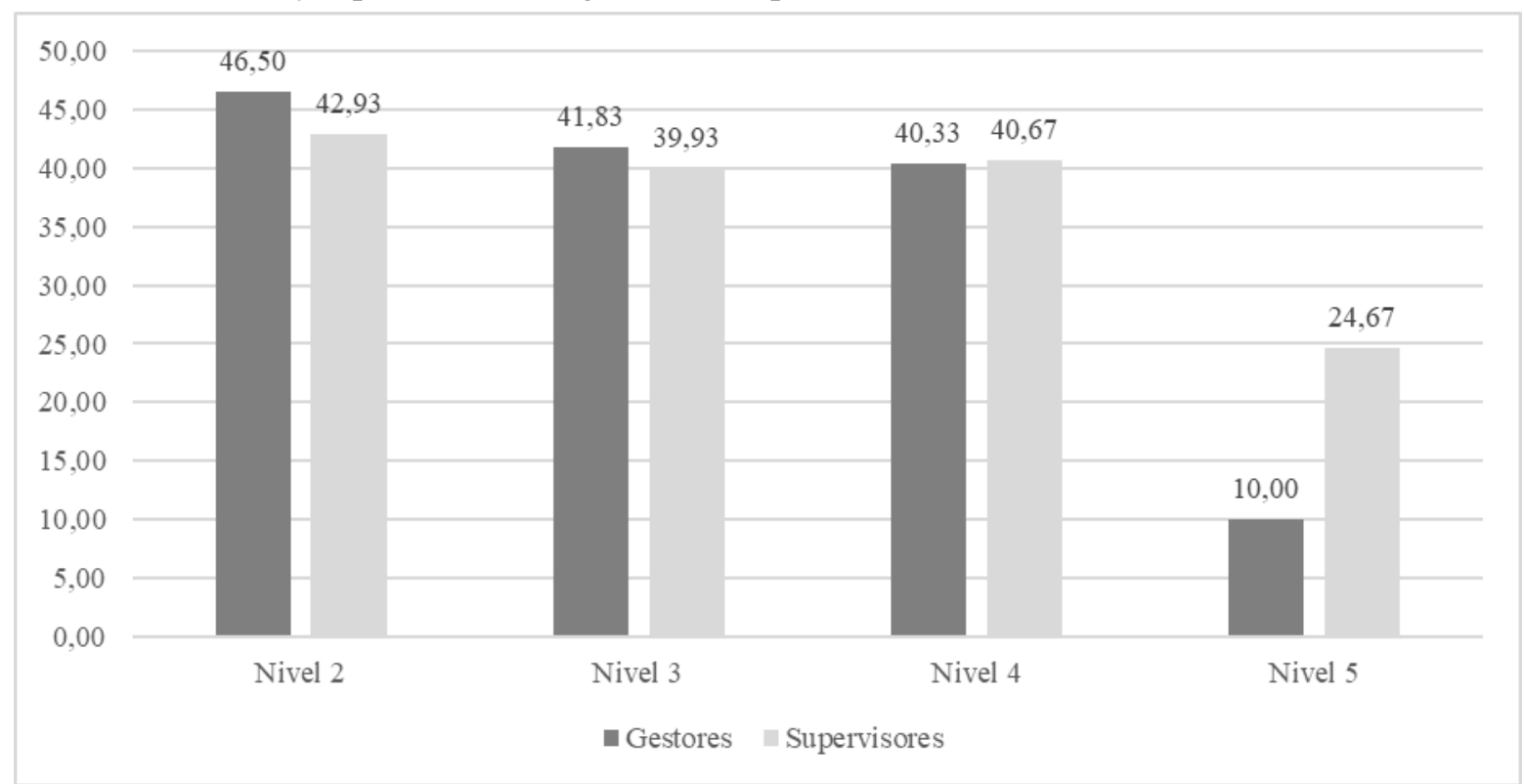

Fonte: Elaborado pelos autores.

Apesar da amostra ser representada na maior parte por respondentes com cargos de supervisores em relação a gerentes, quanto aos resultados encontrados, foi muito semelhante, pois, nos níveis 2, 3 e 4 ficaram muito próximos, como verificado na Figura 3, enquanto o nível 5, foi levemente mais observado por supervisores. Na obra de Prado (2010), há a indicação que este nível 5 representa um status em que a organização atinge a capacidade máxima em gerenciamento de projetos, o que não é o caso desta pesquisa, constatado um longo caminho ainda percorrer para atingir uma plenitude.

O departamento de gestão de projetos atua na implementação de técnicas para gestão de projetos e o desenvolvimento dos mesmos. Porém esse baixo nível de maturidade é explicado pelo pouco tempo da criação do departamento de projetos na empresa estudada, o qual ainda demandará de tempo de desenvolvimento dos profissionais e dos 
processos relacionados aos projetos, vindo de encontro com os achados no estudo de Scotelano et al. (2017). Por ser uma empresa familiar, há uma demora maior para a aprovação dos projetos internos, por necessitar passar pela apreciação da direção e do conselho de administração antes da aprovação, movimento que também é indicado por Kammerland e Essen (2017). Logo surge contribuições para a literatura, motivada pela aplicação do modelo em uma empresa familiar, demonstrando resultados inéditos e passíveis de comparação com outras empresas do segmento alimentício, ou com administração familiar.

Outra diferenciação obtida entre gestores e supervisores está no fato da AFM para os 6 gestores se obteve um nível de 2,39 e para os 15 supervisores este nível esteve em 2,48, conforme a Figura 4.

Figura 4 - AFM de gestores e supervisores

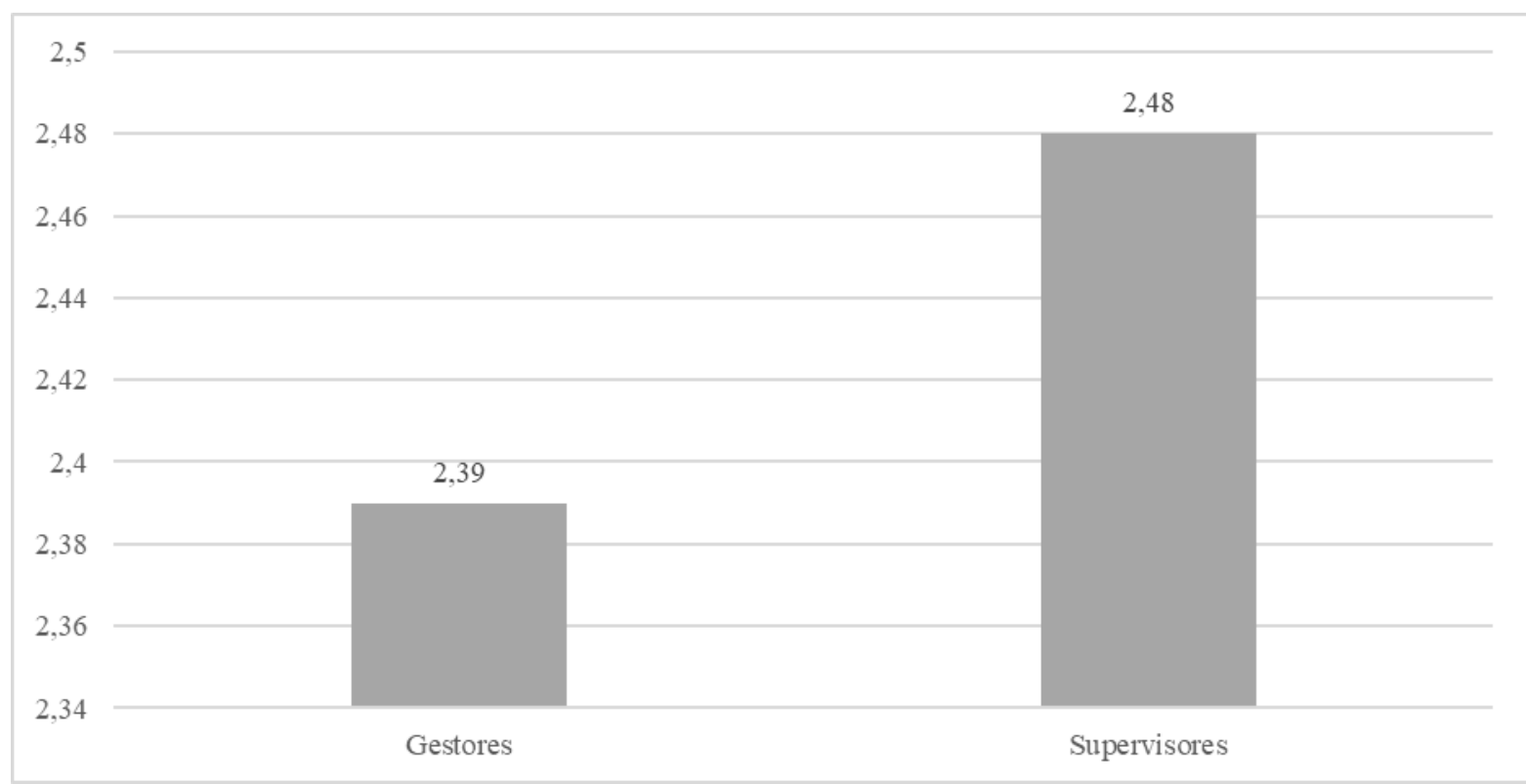

Fonte: Elaborado pelos autores.

Pela AFM geral de 2,45 observada, verifica-se o nível de maturidade para gerenciamento de projetos considerada fraca, com um viés para atingir um patamar regular, pela escala modelada por Prado e Archibald (2013), de acordo com a Tabela 3. O que representou uma similaridade com a pesquisa de Oliveira (2014), que avaliou a maturidade de gerenciamento de projetos no setor de Engenharia de Projetos de um Estaleiro de grande porte no nordeste brasileiro, em que os resultados indicaram para um nível fraco, e que recomendaram desenvolver melhorias. 
Geremia, C. A., Schmitt, D. C., \& Zanella, C. (2020, maio/ago.). Nível de maturidade em gerenciamento de projetos: estudo de caso em empresa familiar de médio porte do ramo alimentício

Tabela 3 - Escala de AFM geral e categoria correspondente

\begin{tabular}{cc}
\hline AFM & Categoria \\
\hline 4,6 a 5 & Excelente \\
4,0 a 4,6 & Ótima \\
3,2 a 4,0 & Boa \\
2,6 a 3,2 & Regular \\
1,6 a 2,6 & Fraca \\
0 a 1,6 & Muito fraca \\
\hline
\end{tabular}

Fonte: Modelo de Prado, MMGP V4, Prado (2010).

Em pesquisas anuais, Prado (2010), quais podem ser comparadas, com a detalha o status da maturidade de diversos maturidade encontrada no setor de pesquisa do setores da economia. A Tabela 4 apresenta o estudo, bem como, com a maturidade a nível nível de maturidade em gerenciamento de global, possibilitando assim a confrontação dos projetos de algumas áreas de negócios, as resultados.

Tabela 4 - Maturidade por área de negócio na iniciativa privada

\begin{tabular}{cc}
\hline Setor & Maturidade \\
\hline Bancos, Finanças & 2,55 \\
Construção & 2,85 \\
Consultoria & 2,45 \\
Defesa, Segurança & 3,15 \\
Educação & 2,45 \\
Energia Elétrica & 2,54 \\
Engenharia & 2,86 \\
Saúde & 2,35 \\
Tecnologia da Informação & 2,54 \\
Telecomunicações & 2,73 \\
Transportes, Armazenagem & 2,38 \\
Maturidade Global Média & 2,60 \\
\hline Média do Setor Avaliado & $\mathbf{2 , 4 5}$ \\
\hline
\end{tabular}

Fonte: Adaptado de Prado (2010). 
Com base na Tabela 3 é possível desenvolver uma análise observando a AFM avaliada neste estudo. Em relação ao nível de maturidade global, encontra-se ligeiramente inferior, com o nível do setor avaliado estando com 2,45, e o nível global estar com 2,60. O desvio padrão de 0,49 representa a heterogeneidade da amostra pesquisada, representadas por tempos de permanência de empresa distintos e por formações acadêmicas diversas, em algumas vezes não vinculadas ao trabalho desempenhado pelo colaborador, corroborando assim com os dados de Campos et al. (2020) que percebe esse heterogeneidade em locais com níveis distintos de formação e funções.

Uma comparação com o setor alimentício em específico, o que seria interessante, não foi possível, devido a não divulgação dos dados neste segmento, por não conter respondentes suficientes na pesquisa de Prado e Archibald (2013). Assim esta pesquisa pode servir de parâmetros para outros estudos, possibilitando comparativos. Como modo de constatação exclusivamente, nota-se que o setor avaliado nesta área de negócio se encontra com nível inferior que as áreas de Bancos/Finanças, Construção, Defesa/Segurança, Energia Elétrica, Engenharia, Tecnologia da Informação e Telecomunicações. De mesmo nível que as áreas de Consultoria e Educação e superior que as áreas de Saúde e Transportes/Armazenagem. Cabe ressaltar que essa constatação não aplica-se para comparativos, pois são setores de análise totalmente distintos. Essa pesquisa avançou na aplicação do método de forma inédita em relação ao estudo de Prado (2010), pois o mesmo não abordou o seu método no setor alimentício, conforme indicado na Tabela 4.

Pelo modelo de maturidade idealizado por Prado (2010), outro índice que é extraído e que serve de análise, é o perfil de aderência aos níveis. Simplificando, seria o quanto pelo setor avaliado, foi aferido ou atingido em cada nível de maturidade, sendo 100 pontos a aderência total. Neste caso, visualizado na Figura 5. 
Figura 5 - Perfil de aderência aos níveis

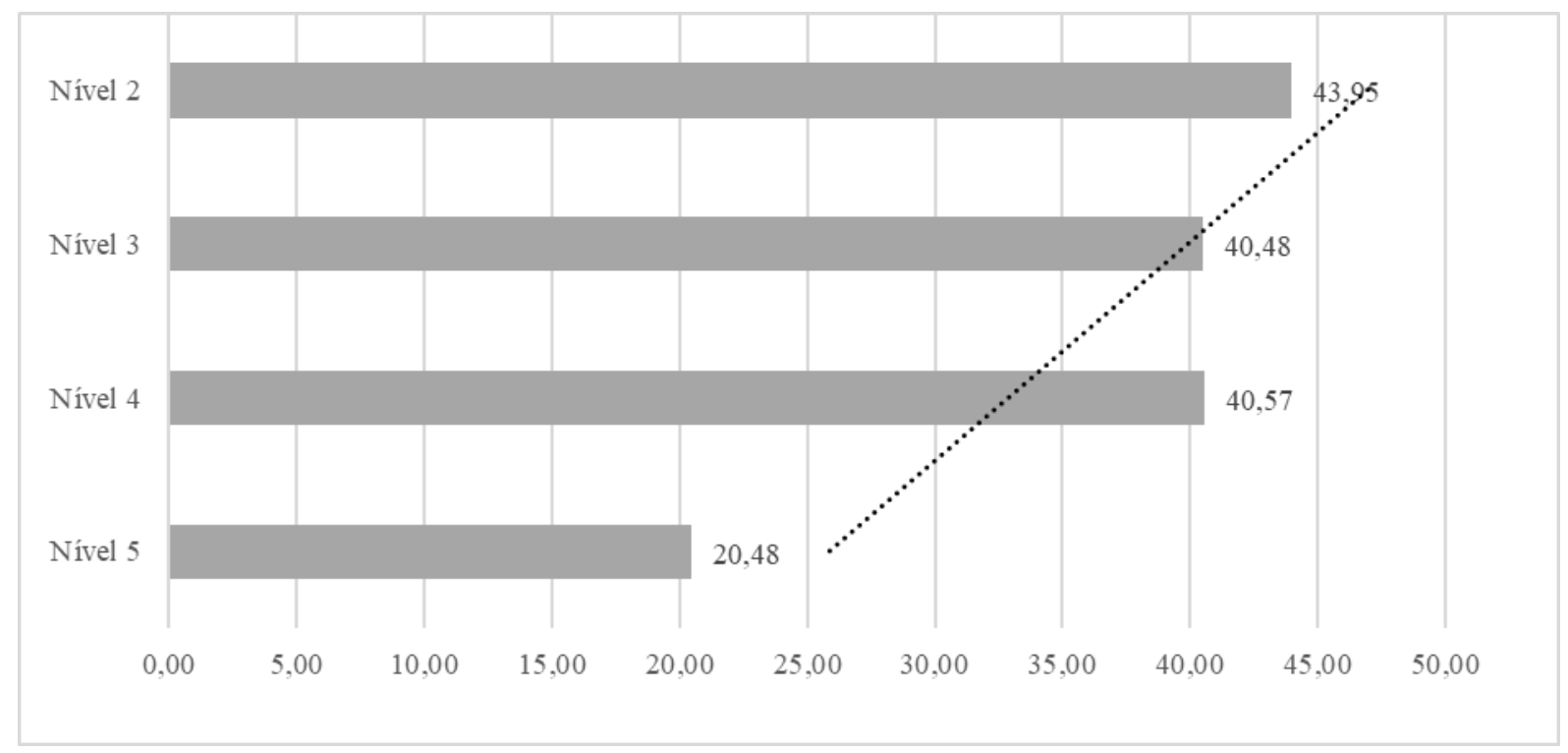

Fonte: Elaborado pelos autores.

Pelos níveis de aderência, contemplados na Figura 5, quantos aos níveis 2,3 e 4 estão em patamares semelhantes, sendo 43, 95, 40, 48 e 40, 57 respectivamente, e o nível 5 com 20 e 48, situando-se em uma aderência inferior às demais. No estudo de Santos, Schramm e Schramm (2019) é indicado que os níveis de maturidade por vezes podem variar, conforme os objetivos, estratégias, disponibilidades de recursos e necessidades específicas que as dispõem, vindo de encontro com os resultados apresentados.
Para situar a aderência de gerenciamento aos níveis, Prado e Archibald (2013) demonstram uma escala em pontuação com intervalo de 0 a 100, de acordo com os pontos aderidos em cada nível (2 a 5) na pesquisa. Na Tabela 4, pode-se constatar, que para os níveis 2, 3 e 4 se enquadraram em uma categoria regular, enquanto o nível 5, inclusive se enquadra na categoria regular, mas com a pontuação de 20,48 de aderência, sugere um viés para a categoria fraca. 
Figura 6 - Perfil de aderência às dimensões

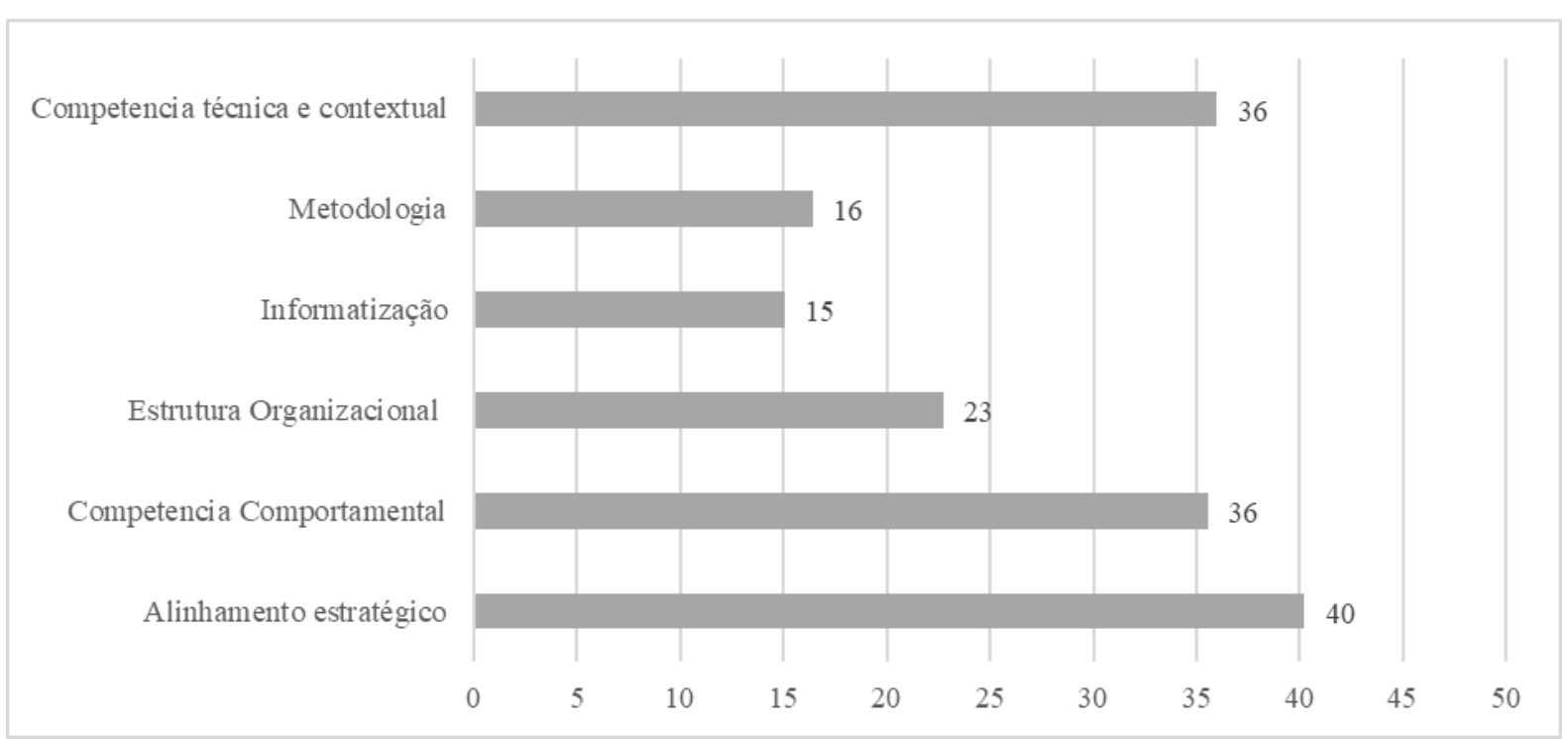

Fonte: Elaborado pelos autores.

Pelo índice de aderência às dimensões, conforme a Figura 6, encontramse os aspectos relacionados metodologia, informatização, estrutura organizacional, em um nível menor com uma aderência de 16, 15 e 23 respectivamente, enquanto as dimensões relacionadas ao alinhamento estratégico (40), competência técnica e contextual (36) e competência comportamental (36), estão em um patamar acima, mas longe ainda de uma aderência na sua plenitude.

Conforme demonstrado por Campos et al. (2020), por meio dos índices destacados, algumas empresas, muitas vezes pelo conhecimento adquirido, se administram problemas encontrados, que pode ser observado nesta pesquisa, com uma aderência maior em aspectos técnicos e de engajamento dos envolvidos, e de menor intensidade em aspectos de denotam maior investimento, que por enquanto, não ser prioridade neste momento, como no caso de informatização e estrutura organizacional. 
Tabela 5 - Escala de perfil de aderência às dimensões

\begin{tabular}{cc}
\hline IAD & Categoria \\
\hline Até 100 & Completa \\
Até 90 & Boa \\
Até 60 & Regular \\
Até 20 & Fraca \\
\hline
\end{tabular}

Fonte: Modelo de Prado, MMGP V4 (Prado 2010).

Como nos níveis de maturidade, às dimensões inclusive podem ser escalonadas através do modelo de Prado (2010). Pela Tabela 5, constata-se que os aspectos relacionados à metodologia e informatização se encontram em uma categoria fraca, enquanto competência técnica e contextual, estrutura organizacional, competência comportamental e alinhamento estratégico se posicionam em uma escala regular. Portanto, proporcionando no momento possibilidades de melhorias em todas as dimensões, para gradativamente aperfeiçoar, ou mesmo como Prado (2010) indica, consolidar os elementos relacionados ao gerenciamento de projetos. Os resultados auxiliaram o preenchimento da lacuna de pesquisa ao apresentar a análise do nível de maturidade da gestão de projetos de uma empresa familiar de médio porte. Além de contribuírem com o avanço dos estudos de Campos et al. (2020), e Silva, Monteiro e Junior (2018) que aplicaram o modelo MMGP em ambientes universitários, onde os níveis de formação mostram-se homogêneos.

\section{Considerações finais}

Este estudo procurou mensurar o nível de maturidade de gerenciamento de projetos de uma empresa familiar do ramo alimentício. Contatou-se que a empresa se encontra em um nível de escala fraca, o que gera a necessidade da organização, um processo de melhoria para adquirir gradativamente avanços na absorção das ferramentas de gestão de projetos. Pelo fato do setor de projetos da organização ser relativamente recente, com 5 anos de sua implantação, pode-se considerar que ainda não esteja suficientemente consolidado, que pode ser paulatinamente alcançado com o passar do tempo.

Quanto às limitações para a realização da pesquisa, pode-se ponderar que foi desenvolvida através de questionário já validado na literatura (Prado, 2010), mas por muitos respondentes, o consideraram ser um tanto extenso e relativamente de linguagem técnica. Apesar de não se encontrar em um patamar desejável, com o nível médio de 2,45 de maturidade, e se enquadrando num nível fraco, em comparação com outras pesquisas descritas no artigo, a empresa possui 
semelhanças com a maioria delas. Consequentemente, a empresa em questão, com suas particularidades, pelo modo de gestão, não apresenta diferenciação de outras pesquisas que da mesma forma identificaram demandas de aperfeiçoamento.

Quanto à análise das dimensões, podese considerar que no momento se encontra um campo de melhorias, pois pela escala de categorização, ainda se encontra em níveis baixos. Partindo prioritariamente das dimensões com menores níveis de aderência, a empresa para melhorar este cenário, no sentido de metodologia e informatização. No primeiro caso, não demandaria de praticamente algum custo, pois aconselha-se unificar a metodologia utilizada, para que todos os envolvidos com cada projeto tenham acesso e entendimento comum. Quanto à informatização, depende muitas vezes de treinamento, o que não se observa ser o caso, por haver conhecimento técnico razoavelmente constituído, assim a aquisição de um software mais sofisticado que possa trazer um volume maior de informações para a tomada de decisão, se mostra interessante. Em alguns aspectos demanda investimento, que se observa por hora, ainda não ser prioridade, procurando administrar a gestão de projetos através do conhecimento, experiência e envolvimento.

As contribuições da pesquisa se destacam pela lacuna preenchida, no caso da aplicação do modelo em uma empresa familiar, observado a escassez de obras neste campo. Representada neste estudo que não difere de outras categorias, pelo fato de outras pesquisas terem tido resultados semelhantes, com nível de maturidade fraca. A contribuição teórica o presente estudo também ocorre em função de ser o primeiro trabalho demonstrando a influência do ambiente de empresas familiares nos resultados do uso da ferramenta MMGP, o qual preencheu uma lacuna da literatura científica, além de seus dados servirem de base para o desenvolvimento da maturidade de projetos em outras empresas familiares.

$$
\text { Como recomendação para novas }
$$
pesquisas, partindo destes achados, que se utilize desta metodologia, ou mesmo outras descritas na literatura, para que possam ser aplicados em outras organizações, e outros setores de negócios, e especificamente em empresas de gestão familiar, para gradativamente aumentar os estudos nesta direção. Proporcionando um paralelo, e podendo evoluir ao seguir os passos de organizações que são vanguarda no quesito gerenciamento de projetos.

\section{Referências}

Abrahão, P.V.S. \& Oliveira, E.A.A.Q. (2016). Maturidade em gerenciamento de projetos: Um estudo de caso em um departamento de desenvolvimento de novos produtos. Revista Brasileira de Gestão e Desenvolvimento Regional, 12(5), 204-228.

Arruda, G.M., Barbosa, J.F., Oliveira, P. E. A., Silva, D.C. \& Hollanda, A.C.R. (2019). Project management maturity analysis of engineering research laboratories at a federal university in the northeast region of Brazil. Brazilian 
Journal of Development, 5(11), 272627247.

Brown, C.J. (2008). A comprehensive organisational model for the effective management of project management. South African Journal of Business Management, 39(3), 1-10.

Campos, M.C., Dantas, A.B., Silva, L.S.V.C.V. \& Milito, C.M. (2020). Avaliação de Maturidade em Gestão de Projetos na Universidade Federal de Alagoas utilizando o Método PradoMMGP. Revista de Gestão \& Projetos, 11(1), 1-16.

Cardoso, D.R., Ziviani, F. \& Duarte, L.O.B. (2017). Gerenciamento de Projetos: Uma Análise da Maturidade do Setor de Mineração. Revista de Gestão e Projetos, 8(1), 01-15.

Costa, S.R. \& Ramos, A.F.B. (2013). Modelo de Maturidade em gerenciamento de projeto: um estudo de caso aplicado a projetos de petróleo e energia. Sistemas \& Gestão, 8(3), 234243.

Crawford, L. (2006). Developing organizational project management capability: theory and practice. Project Management Journal, 36(3), 74-97.

Estol, K.M.F. \& Ferreira, M.C. (2006). O processo sucessório e a cultura organizacional em uma empresa familiar brasileira. Revista de administração contemporânea, 10(4), 93-110.

Farias, A.S., Batista, F.A.C., Neto, L.L.S. \& Monteiro, J.A.A. (2018). Análise do nível de maturidade em gerenciamento de projetos da agência de saneamento de paragominas estado do Pará. Revista Observatorio de la Economía Latinoamericana, (noviembre 2018), 116.

Gil, A. C. (2002). Como elaborar projetos de pesquisa. São Paulo: Atlas.
Ireland, R.D., Hitt, M.A., \& Sirmon, D.G. (2003). A model of strategic entrepreneurship: the construct and its dimensions. Journal of Management, 29(6), 963-989.

Kammerland, N., \& Essen, M. V. (2017). Research: family firms are more innovative than other companies, Harvard Business Review, 1-6.

Karlsen, J.T. (2010). Project owner involvement for information and knowledge sharing in uncertainty. International Journal of Managing Projects in Business, 3(4), 642-660.

Oliveira, J.P.N. (2014). Avaliação do nível de maturidade em gerenciamento de projetos no setor de engenharia de projetos de um estaleiro de grande porte no Nordeste Brasileiro. Revista de Gestão e Projetos, 5(3), 01-13.

Patrício, R.A.H. \& Neto, J.A.S.F. (2019). Maturity in project management in the public administration: the case of Fiocruz Brasília. Journal Health Npeps, 4(1), 269-281.

Paulk, M.C., Weber, C.V., Curtis, B. \& Chrissis, M.B. (1995). The capability Maturity

Model: Guidelines for improving the Software Process. Pittsburgh: AddisonWesley.

Pires, K.L.S. (2014) A influência da gestão de portfólio na alocação de recursos em uma organização pública de TI. 2014. Dissertação de Mestrado, Universidade Fumec, Belo Horizonte, MG, Brasil.

PMI, Project Management Institute. (2017). A guide to the Project Management Body of Knowledge (PMBOK® Guide). $6^{\circ}$ ed. Project Management Institute.

Prado, D. (2010). Maturidade em Gerenciamento de Projetos. Nova Lima: INDG. 
Prado, D., \& Archibald, R. (2013). Relatório Geral 2012 - Versão

Resumida. Publicado em: http://www.maturityresearch.com/novos ite/2012/download/PesquisaMaturidade2012_RelatorioGeral_V3.pdf

Rabechini, R., \& Pêssoa, M.S.P. (2005). Um modelo estruturado de competências em gerenciamento de projetos. Revista Produção, 15(1), 34-43.

Sá Freire, P., Pereira S.A., Keiko N.M., \& Spanhol, F.J. (2010). Processo de sucessão em empresa familiar: gestão do conhecimento contornando resistências às mudanças organizacionais. Journal of Information Systems and Technology Management, 7(3), 713-735.

Santos, D.F., Schramm, F. \& Schramm, V.B. (2019). Análise da maturidade em gestão de projetos de uma empresa da construção civil utilizando a metodologia MMGP. Interfaces Científicas-Exatas e Tecnológicas, 3(3), 49-64.

Scotelano, L.S., Conceição, R.D.P., Leonídio, U.C. \& Jesus, C.S. (2017). Project management maturity model: the case in an automotive industry in Brazil. Brazilian Journal of Operations \& Production Management, 14(4), 500507.

Sgura, R.V., Araujo, F.O. \& Lopes, R.O.A. (2015). Avaliação de Grau de Maturidade em Gerenciamento de Projetos em Empresa Fabricante de Cabos Submarinos para Poços de Exploração de Petróleo. Revista IPTEC, $3(1), 51-73$.

Silva, A.S., \& Feitosa, M.G.G. (2012). Maturidade no Gerenciamento de Projetos: um estudo das práticas existentes nos órgãos do Governo de Pernambuco. Revista de Gestão e Projetos-GeP, 3(2), 207-234.

Silva, J.L.G., Monteiro, R.C.R.V. \& Júnior, R.T.T. (2018). Maturidade em gerenciamento de projetos universitários de pesquisa e extensão. Revista

Brasileira de Gestão e Desenvolvimento Regional, 14(5), 160-173.

Srivannaboon, S. (2009). Achieving competitive advantage through the use of project management under the plando-check-act concept. Journal of General Management. 34(3), 1-20.

Vinagre, L.M., Silva, S.W., Portugal, P.S., Souza, R.S., Gonçalves, J.E. \& Pereira, W.F. (2017). O processo sucessório em uma empresa familiar: um estudo de caso em um supermercado de VarginhaMG. Revista da Universidade Vale do Rio Verde, 15(1), 689-700.

YIN, R. K. (2005). Estudo de Caso: Planejamento e Métodos, $5^{\circ}$ ed., Porto Alegre, Bookman. 